\title{
RP-HPLC METHOD DEVELOPMENT AND VALIDATION OF ASIATIC ACID ISOLATED FROM THE PLANT CENTELLA ASIATICA.
}

\author{
SRINIVAS HEBBAR ${ }^{1}$, AKHILESH DUBEY ${ }^{1}{ }^{*}$, RAVI G. S. ${ }^{1}$, HEMANTH KUMAR ${ }^{2}$, SANTANU SAHA ${ }^{3}$
}

1Department of Pharmaceutics, N. G. S. M. Institute of Pharmaceutical Sciences, Nitte (Deemed to be University), Deralakatte, Mangaluru 575018, Karnataka, India, ${ }^{2}$ Department of Pharmaceutical Chemistry, N. G. S. M. Institute of Pharmaceutical Sciences, Nitte (Deemed to be University), Deralakatte, Mangaluru 575018, Karnataka, India, ${ }^{3}$ Department of Pharmcognosy, N. G. S. M. Institute of Pharmaceutical Sciences, Nitte (Deemed to be University), Deralakatte, Mangaluru 575018, Karnataka, India

Email: akhilesh@nitte.edu.in

Received: 19 Dec 2018, Revised and Accepted: 18 Mar 2019

\section{ABSTRACT}

Objective: Asiatic acid is a triterpene saponin and the main constituent of the species Centellaasiatica. The current study aimed to isolate, characterize and develop an analytical method for asiatic acid in the shorter run time with good efficiency.

Methods: In this study isolation of asiatic acid was achieved by TLC and thus isolated asiatic acid was characterized by ${ }^{1} \mathrm{HNMR}$ spectral analysis and LCMS. An isocratic RP-HPLC method was established for the assessment of asiatic acid from the methanol extract of Centellaasiatica. The chromatographic separations were achieved by RP-C18 column 250x4.6 mm (5 $\mu$ Particle size) Shimadzu UFLC pump LC 20AD and mobile phase composed of $0.1 \%$ orthophosphoric acid: acetonitrile (50:50). The analysis of column effluents was achieved using a PDA detector (Photo Diode Array) at $210 \mathrm{~nm}$, and the flow rate was recorded $1 \mathrm{ml} / \mathrm{min}$.

Results: Soxhlet extraction process followed by fractional extraction using different solvents was performed. Methnol extract was taken to isolate asiatic acid by TLC (RF 0.97) and base peak from mass spectra was found to be $489 \mathrm{M}^{+}$which was confirmed successful isolation. Retention time of asiatic acid was found to be $9.6 \pm 0.22 \mathrm{~min}$. This method obeyed linearity over the concentration range of $10-50 \mu \mathrm{g} / \mathrm{ml}$ and regression coefficient was obtained from the alinearity plot for asiatic acid which was found to be $0.9987 \mathrm{LoD}$ and LoQ were obtained to be $0.784507 \mu \mathrm{g} / \mathrm{ml}$ and $2.615 \mu \mathrm{g} / \mathrm{ml}$ respectively. RSD of mean assay values was found to be $1.02 \%$. Since there were no marked changes in the performance characteristics of the method.

Conclusion: Isolation, characterization and identification of asiatic acid were achieved significantly which will be useful for the standardization of herbal formulation containing asiatic acid.

Keywords: Asiatic acid, RPHPLC, ${ }^{1}$ HNMR, LCMS, PDA

(C) 2019 The Authors. Published by Innovare Academic Sciences Pvt Ltd. This is an open access article under the CC BY license (http://creativecommons.org/licenses/by/4.0/) DOI: http://dx.doi.org/10.22159/ijap.2019v11i3.31525

\section{INTRODUCTION}

Centellaasiatica, generally known as Gotu kola is a small; herbaceous plant belongs to a family Apiaceae. It is a frost-tender perennial plant prevalent in tropical and sub-tropical countries. In India,it is well known as Brahmi, and since ancient times, it has been used as a memory enhancer [1]. Centellaasiatica plants are the richest bioresource of drugs. Separation of medicinally active portions of the plant was done by extraction method by using selective solvents [2]. The triterpenoid compounds are responsible for the pharmacological activity of Centellaasiatica. The triterpenoid ingredients in Centellaasiatica have been identified by thin layer chromatography using mass spectrometry and NMR to determine the compounds [3]. The triterpenes isolated from Centellaasiatica are mainly pentacyclictriterpenic acids and that the asiatic acid, asiaticoside, madecassic acid, madecassoside, brahmoside, brahmic acid, brahminoside and other triterpenic glycosides of Centellaasiatica are of the ursane-or oleanane-type. In triterpenoids, asiatic acid (AA), has gained substantial value due to its polypharmacological properties and therapeutic potential in various diseases. AA has been identified as the most active compound in the plant associated with the power of rejuvenating neuron [4]. It is used to control oxidative stress response that is associated with neurodegenerative changes in Alzheimer's disease. Neuroprotective efficacy of AA was shown against glutamate-induced or betaamyloid-induced neurotoxicity and focal cerebral ischemia. The useful application of AA was shown in wound healing, various skin lesions, treatment for inflammations, liver fibrosis, cerebral ischemia, dementia, hyperglycaemia, metabolic syndrome, diarrhoea, asthma, and tuberculosis [5].

Chromatography is considered as one of the well-established analytical separation techniques. High-performance liquid chromatography has been the most comprehensive chromatographic technique initially employed for the analysis of phytoconstituents [6]. High-performance liquid chromatography/ electrospray ionization tandem mass spectrometry (HPLC/ESIMS/MS) techniques are adopted for quantifying triterpenoids from biological matrices [6]. Working of Reversed-phase highperformance liquid chromatography (RP-HPLC) includes the separation of molecules based on the hydrophobicity. The separation process involves the hydrophobic binding of the solute molecule from the mobile phase to the immobilized hydrophobic ligands connected to the stationary phase The separations are prompt than the classical method and provide the high degree of sensitivity with enhanced accuracy [7].

The present study aimed at the development of suitable extraction, isolation and characterization procedure to obtain the purified compound and to establish suitable RP-HPLC method for the quantitation of asiatic acid from Centellaasiatica.

\section{MATERIALS AND METHODS}

\section{Materials}

HPLC grade methanol, orthophosphoric acid, acetonitrile and water were procured from E. Merck Ltd., Mumbai, India. 10\%v/v sulphuric acid was purchased from Merck Ltd., Mumbai, India. A reference standard of asiatic acid was purchased from Sigma-Aldrich Chemise, USA. All the chemicals including solvents used were of analytical or HPLC grade.

\section{Methods}

\section{Collection and identification of plant materials}

The plant specimen was collected early morning from fertile land in the month of June. The specimen was identified. Voucher specimen number of the whole plant 16PH005R and it was confirmed, authenticated by Dr. Krishna Kumar G, Professor, Department of 
Applied Botany, Mangalore University, Karnataka, India. The whole plant was used for the research activity.

\section{Preparation of Centellaasiatica extract}

The extraction process was conducted by soxhlet extraction method with the repeated cycle by using fresh solvent. Fresh leaves of the Centellaasiatica plants were sun-dried for two weeks and grinded to powder. $50 \mathrm{~g}$ of clean powder was subjected to extraction using methanol in a soxhlet apparatus. 40 cycles were run for the extraction at the temperature of $65^{\circ} \mathrm{C}$ [8].

\section{Fractional extraction process}

The dried powdered leaves extract was further fractionally extracted with five different solvents such as petroleum ether, chloroform, ethyl acetate, n-butanol and methanol subsequently throughout $24 \mathrm{~h}$ for $5 \mathrm{~d}$. Extracts were filtered, concentrated and subjected to various phytochemical analyses. The major secondary metabolites like carbohydrate, tannins, steroids, terpenoids, alkaloids, flavonoids, saponins, quinone and phenolic compounds were assessed in various extractions was confirmed by standard protocols [8].

\section{Isolation and purification of asiatic acid}

Initially, preparative $0.2 \mathrm{~mm}$ silica gel coated TLC plates of $5 \times 5 \mathrm{~cm}$ size (GF254, Merck, Germany) was procured. An aliquot of a standard solution of asiatic acid and a sample solution of Centellaasitica extract were spotted onto the silica gel plate and allowed to dry. The mobile phase which was used to develop TLC plate was ethyl acetate: methanol: water $(8: 1: 1)$ in a saturated glass chamber. Later, the developed plate was dried and spots were visualized by spraying with a solution of $10 \% \mathrm{v} / \mathrm{v}$ sulphuric acid and dried under oven at $105{ }^{\circ} \mathrm{C}$. The Rf values of isolated compounds and standard were calculated and compared [8]. For purification, the extract was applied manually on a TLC glass plate $(20 \times 20 \mathrm{~cm} ; 1500$ $\mu \mathrm{m}$ thickness) along with inorganic fluorescent indicator binder (Analtech, Sigma-Aldrich, Germany). The same mobile phase was taken which was used in the analytical TLC. Plate was kept for air drying for 30 to $40 \mathrm{~min}$ for the separation. Well-developed band was scratched and dissolved in HPLC grade methanol, centrifuged at 12000rpm for $15 \mathrm{~min}$ to remove silica. Supernatant was filtered from $0.22 \mu \mathrm{m}$ filter and dried. All the samples were passed under nitrogen gas for $5 \mathrm{~min}$ and then dissolved in methanol for further characterization and quantitative HPLC analysis [9].

\section{Characterization of isolated compound}

\section{Liquid chromatography-mass spectroscopy}

Identification and integration of chromatographic peaks were achieved by using Thermo/Finnigan Surveyor system containing a degasser, binary pump, autosampler, and column heater. The column outlet was coupled to a Thermo fleet (LCQ-Fleet) Ion Trap mass spectrometer equipped with an ESI ion source. By using Data Analysis software (Qual Browser; Thermo Electron, San Jose, CA) Data acquisition and mass spectrometric evaluation were carried out [10]. For the chromatographic separation, a phenomenexluna 5$\mu \mathrm{m}$ C8 column $(250 \times 4.6 \mathrm{~mm})$ was used. The column was held for 1 min at $95 \%$ solvent A ( $0.1 \%$ orthophosphoric acid in water) and $5 \%$ solvent B (acetonitrile). Then followed by $11 \mathrm{~min}$ step gradient from $5 \%$ B to $100 \%$ B, then 4 min with $100 \%$ B. Elution was achieved with a linear gradient from $100 \%$ B to $5 \%$ B for 2 min. The flow rate was kept $0.2 \mathrm{ml} / \mathrm{min}$ and $5 \mu \mathrm{l}$ volume was injected. This condition was maintained throughout the MS experiment: for electrospray ionization with positive ion polarity the capillary voltage was set to $20 \mathrm{~V}$, the capillary temperature to $300^{\circ} \mathrm{C}$, the nebulizer pressure to $40 \mathrm{psi}$, and the drying gas flow rate to $15 \mathrm{~L} / \mathrm{min}$. MS data were documented in the complete scan mode (m/z 50 to 1000). A quantitative analysis was performed by the monitoring of each protonated molecular ion the positive ion mode [11].

\section{H NMR}

${ }^{1} \mathrm{H}$ NMR spectra of isolated asiatic acid were recorded on a NMR-400 $\mathrm{MHz}$ (with multi-nuclei analysis from ${ }^{1} \mathrm{H}$ ) and chemical shifts were recorded as $\delta$ values. Using TMS as an internal standard and deuterated methanol was taken as solvent [12].

\section{HPLC method development}

\section{Preparation of standard stock solution}

Accurately weighed $10 \mathrm{mg}$ of standard asiatic acid was transferred to a $10 \mathrm{ml}$ volumetric flask and dissolved in methanol. Volume was made with methanol to obtain standard stock solution of concentration 1000 $\mu \mathrm{g} / \mathrm{ml}$. This stock solution was further diluted for the studies [12].

\section{Calibration of asiatic acid}

A stock solution consisting of asiatic acid $(1000 \mu \mathrm{g} / \mathrm{ml})$ was prepared. From this $10,20,30,40,50 \mu \mathrm{g} / \mathrm{ml}$ aliquots were made by adjusting with methanol in $10 \mathrm{ml}$ volumetric flasks and from each $10 \mu \mathrm{l}$ of the solution was injected into the RP-HPLC system. Linearity was established by triplicate injections of solutions containing standard asiatic acid. The developed RP-HPLC method was validated by determination of selectivity, linearity, limit of quantitation and detection, precision, accuracy, recovery, robustness and stability [13].

\section{System suitability studies}

System suitability was acchieved by injecting six replicate injections of standard solution of asiatic acid and followed by determination of $\%$ relative standard deviation (\% RSD) of peak areas, resolution factor, tailing factor and theoretical plates [13].

\section{LoD and LoQ}

As per ICH of technical requirements for the registration of pharmaceuticals for human use recommendations, Limit of Detection (LoD), and Limit of Quantitation (LoQ) are terms used to illustrate the minute concentration of a anayte that can be consistently measured by an analytical procedure. From the calibration curvesLoD and LoQ values were calculated by using $\mathrm{k}^{*} \mathrm{SD} / \mathrm{b}$ where, $\mathrm{k}=3$ for LoD and 10 for LoQ, SD stands for standard deviation of the response of the minimum detectable drug concentration and b represents the slope of calibration [13].

\section{Accuracy (Recovery)}

Accuracy of the process was determined by recovery experiments by considering standard addition method at three different levels (80, 100 and 120\%). Known volumes of standard solutions containing asiatic acid $(8,10$, and $12 \mu \mathrm{g})$ were added to pre-quantified sample solutions (isolated asiatic acid) to reach the 80, 100 and $120 \%$ levels. These samples were analysed in triplicate and recovery was calculated. Then the difference between the spiked and un-spiked sample was determined for different recovery [13].

\section{Precision (Repeatability)}

Method Precision (intraday study) of the assay method was demonstrated by analysing six different sample solutions containing isolated asiatic acid equivalent to $10 \mu \mathrm{g} / \mathrm{ml}$ and from the area attained, concentration was determined and the results were exhibited as \% RSD (Relative Standard Deviation) [13].

\section{Intermediate precision (Ruggedness)}

Intermediate precision (interday study) of the method was validated by performing an experiment on different days by different analysts and on different C18 columns [13].

\section{Robustness}

Robustness of the method was determined by intentionally varying the chromatographic conditions. The flow rate of the mobile phase was changed from 1.0 to $0.9 \mathrm{ml} / \mathrm{min}$ and $1.1 \mathrm{ml} / \mathrm{min}$. The composition of mobile phase was changed from 50:50 $(0.1 \%$ orthophosphoric acid: acetonitrile) to 47.5:52.5 and 52.5:47.5 (0.1\% orthophosphoric acid: acetonitrile) (i.e. $5 \%$ change). Three times standard solution was injected into the column to study for the robustness and the responses were noted [13].

\section{RESULTS AND DISCUSSION}

After identification of the plant, leaves were collected, dried and subjected to soxhlet extraction process. The dark green liquid extract gets concentrated, and methanol was evaporated resulted in 
dried powder which was then preserved in a dessicator [14]. One part of extraction is further subjected to fractional extraction process by using petroleum ether, chloroform, ethyl acetate, nbutonal and methanol to assess phytoconstituents. The extracts of Centellaasiatica showed different phyto profiles with reference to the solvents. Out of the five solvents (petroleum ether, chloroform, ethyl acetate, n-butonal, methanol) used methanol extract demonstrated the maximum occurrence of phytoconstituents. It is because of amphilic nature methanol dissolves a larger portion of polar compounds and a certain group of non-polar compounds. Phytoconstituents' screening was shown in table 1 . Hence methanol extract was selected for further analytical study [14].

Table 1: Phytochemical screening of Centellaasiatica

\begin{tabular}{|c|c|c|c|c|c|}
\hline \multirow[t]{2}{*}{ Test } & \multicolumn{5}{|l|}{ Solvents } \\
\hline & Petroleum ether & Chloroform & Ethyl acetate & n-butanol & Methanol \\
\hline Alkaloids & - & + & + & - & + \\
\hline Carbohydrate & - & - & - & + & + \\
\hline Flavonoids & - & + & - & + & + \\
\hline Glycosides & - & + & + & + & + \\
\hline Phenolic compounds & - & - & + & - & + \\
\hline Protein & - & + & - & - & - \\
\hline Saponins & - & - & + & + & + \\
\hline Steroids & - & + & + & + & + \\
\hline Tannins & - & - & - & - & + \\
\hline Terpenoids & - & - & - & - & + \\
\hline
\end{tabular}

+indicates presence,-indicates absence

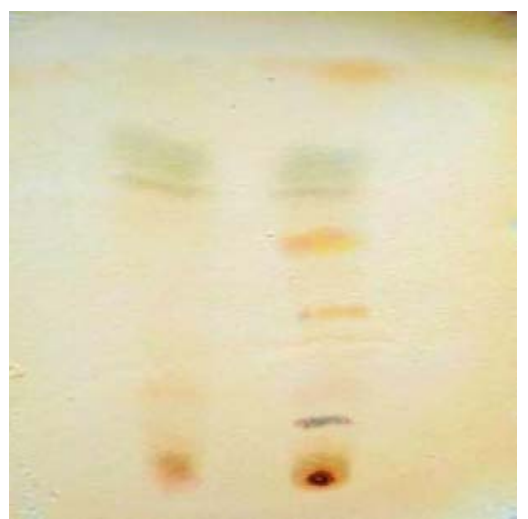

Fig. 1: Preparative TLC run with standard asiatic acid and Centellaasiatica extract

\section{TLC extraction of asiatic acid}

The Rf value of both standard and sample were found to be similar (0.97) which confirmed that the isolated compound is structurally related to the reference standard of asiatic acid [15]. The TLC profile of the compound is represented in fig. 1

\section{Characterization of isolated compound}

Characterization of isolated compound was done by LCMS and NMR spectra analysis. Mass spectral data showed the molecular ion peak and base peak at $\mathrm{m} / \mathrm{z} 489 \mathrm{M}+$ which confirmed successful isolation of asiatic acid from Centellaasiatica. (fig. 2) [15]. The ${ }^{1} \mathrm{H}$ NMR spectra of isolated component was recorded at $400 \mathrm{MHz}$ frequency on 0 -scale and ${ }^{1} \mathrm{H}$ shifts are reported in parts per million (ppm). It showed the chemical shift values as follows: $1.257-1.198(2 \mathrm{H}, \mathrm{t}, \mathrm{J} 1=10.8 \mathrm{~Hz}$, $\mathrm{J} 2=12.8 \mathrm{~Hz}, \mathrm{H}-1), 3.525-3.475(2 \mathrm{H}, \mathrm{H}-2,3, \mathrm{br}, \mathrm{J} 1=9.6 \mathrm{~Hz}, \mathrm{~J} 2=5.6 \mathrm{~Hz})$ 4.221-4.211 (1H, d, J=4Hz, OH-2), 4.168-4.159 (1H, d, J=3.6Hz, OH3), $1.579-1.469(\mathrm{H}, \mathrm{m}, \mathrm{H}-5,6,7,15,16), 1.429(1 \mathrm{H}, \mathrm{s}, \mathrm{H}-9), 1.392(1 \mathrm{H}, \mathrm{s}$, $\mathrm{H}-18), 1.782-1.772(1 \mathrm{H}, \mathrm{d}, \mathrm{J}=4 \mathrm{~Hz}, \mathrm{H}-11 \mathrm{a}), 1.813-1.804(1 \mathrm{H}, \mathrm{d}, \mathrm{J}=3.6 \mathrm{~Hz}$, $\mathrm{H}-11 \mathrm{~b}) ; 4.421-4.396$ (1H, br t, J = 4.8 Hz, H-12); 2.139-2.111(1H, d, J $=11.2 \mathrm{~Hz}, \mathrm{H}-18) ; 3.073$ and 3.036 (1H each, d each, $\mathrm{J}=10.4 \mathrm{~Hz}, \mathrm{H}-23 \mathrm{a}$ and $\mathrm{H}-23 \mathrm{~b}) ; 1.307\left(3 \mathrm{H}, \mathrm{s}, \mathrm{CH}_{3}-24\right) ; 1.952-1.948\left(3 \mathrm{H}, \mathrm{d}, \mathrm{CH}_{3}-25\right)$; $1.981\left(3 \mathrm{H}, \mathrm{s}, \mathrm{CH}_{3}-26\right) ; 1.922\left(3 \mathrm{H}, \mathrm{s}, \mathrm{CH}_{3}-27\right) ; 1.894-1.876(3 \mathrm{H}, \mathrm{d}$, $\left.\mathrm{J}=7.2 \mathrm{~Hz}, \mathrm{CH}_{3}-29\right) ; 1.839\left(3 \mathrm{H}, \mathrm{s}, \mathrm{CH}_{3}-30\right.$ ). The obtained $\delta$ values matches with the described values of asiatic acid [15]. From this result it was further confirmed that the isolated component is asiatic acid represented in fig. 3

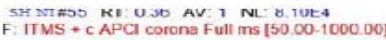
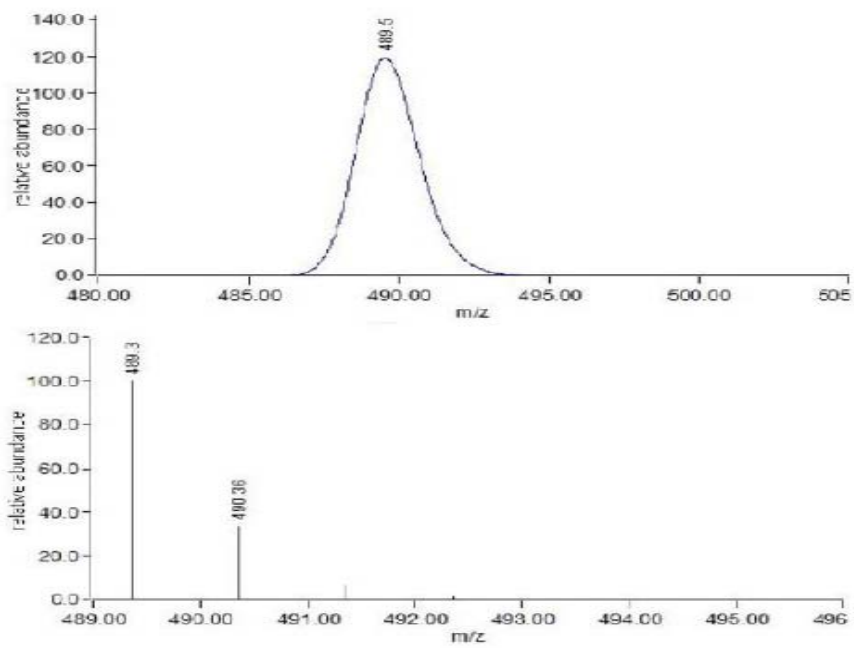

Fig. 2: LC MS spectra of isolated asiatic acid 


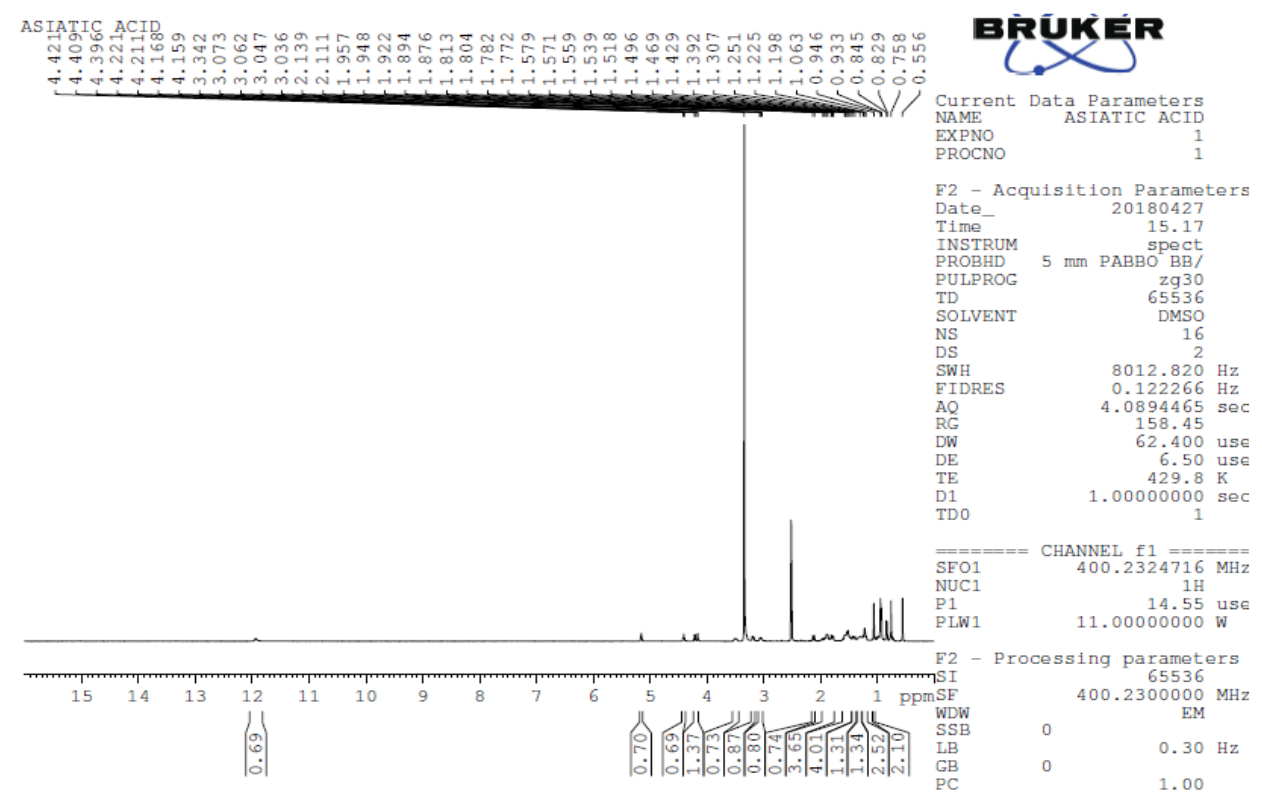

Fig. 3: ${ }^{1} \mathrm{H}$ NMR spectra of isolated asiatic acid

\section{RP-HPLC Method development}

Analysis was done by HPLC method using the conditions given in table 2 .
Several trials are conducted to develop a suitable method and to select a suitable mobile phase. It is because of the complexity of the chemical composition of the herbals and the affinity of the components towards various solvents [16].

Table 2: Optimized chromatographic conditions

\begin{tabular}{ll}
\hline Parameter & Description \\
\hline Instrument & Shimadzu UFLC pump LC 20AD \\
Autosampler & S/l 20AC HT \\
Software used: & lab solutions 5.81 \\
Column & Phenomexluna C18 250×4.6 mm $(5 \mu$ Particle size $)$ \\
Flow rate & $1 \mathrm{ml} / \mathrm{min}$ \\
Injection volume & $10 \mu \mathrm{l}$ \\
Column oven temperature & $30{ }^{\circ} \mathrm{C}$ \\
Detector & PDA detector (SPD-M20A) \\
Wavelength & $210 \mathrm{~nm}$ \\
Mobile Phase & $0.1 \%$ Orthophosphoric acid: Acetonitrile $(50: 50 \%)$ \\
\hline
\end{tabular}

*PDA $=$ Photo Diode Array

The proportions of the organic and aqueous phases were adjusted to obtain a rapid and simple assay method with the reasonable runtime, suitable retention time and sharp peak. Well-developed peak symmetry were obtained by using the mobile phase composition $0.1 \%$ orthophosphoric acid: acetonitrile $(50: 50 \mathrm{v} / \mathrm{v})$.

\section{Calibration of asiatic acid}

HPLC profile for both standard and isolated asiatic acid indicated a single peak at retention time of $9.5 \mathrm{~min}$ (fig. 4) (fig. 5) Linearity regression data, summarized in table 3 . This showed a good linear relationship between concentration and peak areas over a concentration range of 10-50 $\mu \mathrm{g}$ for asiatic acid (fig. 6) [16]. The correlation coefficient $\left(\mathrm{r}^{2}\right)$ was found to be 0.998 .

\section{System suitability study}

System suitability tests were carried out on freshly prepared standard solutions $(n=6)$ asiatic acid. System suitability parameters obtained with $10 \mu \mathrm{l}$ injection volumes are summarized in table 4 .

Table 3: Regression analysis of the calibration curves for asiatic acid

\begin{tabular}{ll}
\hline Parameter & Values \\
\hline Linearity range of Asiatic acid & $10-50 \mu \mathrm{g} / \mathrm{ml}$ \\
Regression equation & $\mathrm{y}=3790.1 \mathrm{x}-3001.9$ \\
Correlation coefficient $\mathrm{r}^{2}$ & 0.9987 \\
Slope & 3790.1 \\
\hline
\end{tabular}

${ }^{*}$ Acceptance criteria $\mathrm{r}^{2}>0.9$ 


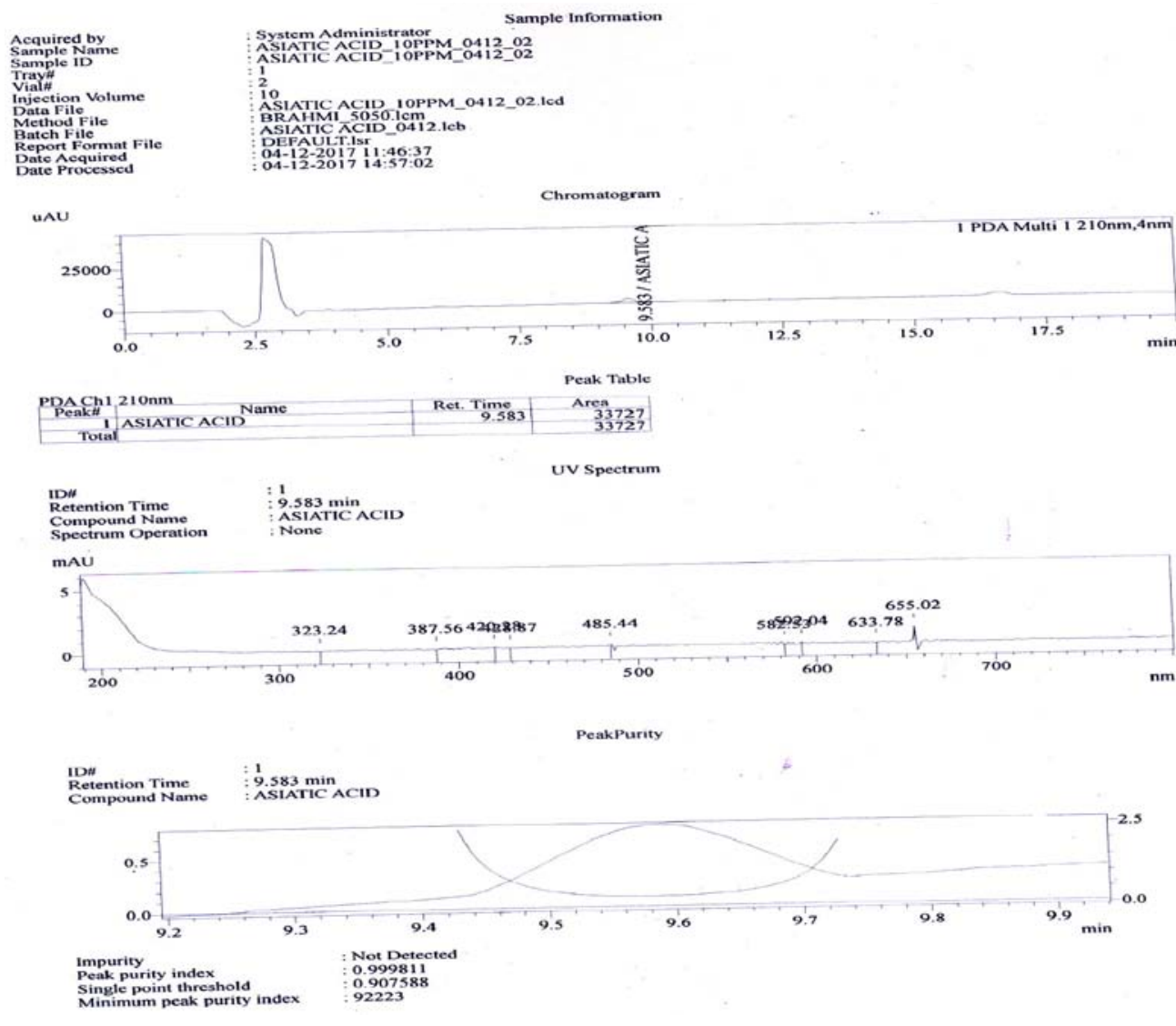

Fig. 4: Chromatogram, UV spectrum and peak purity of asiatic acid

$====$ Shimadzu LCsolution Analysis Report $====$

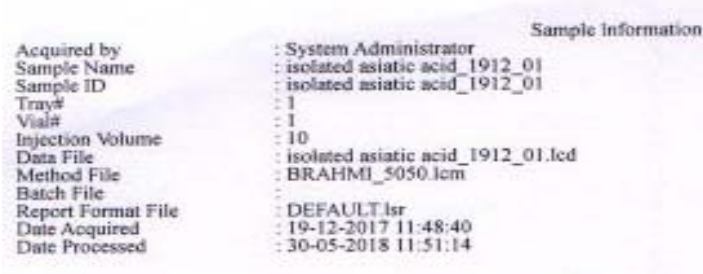

u^บ

Chromatogram

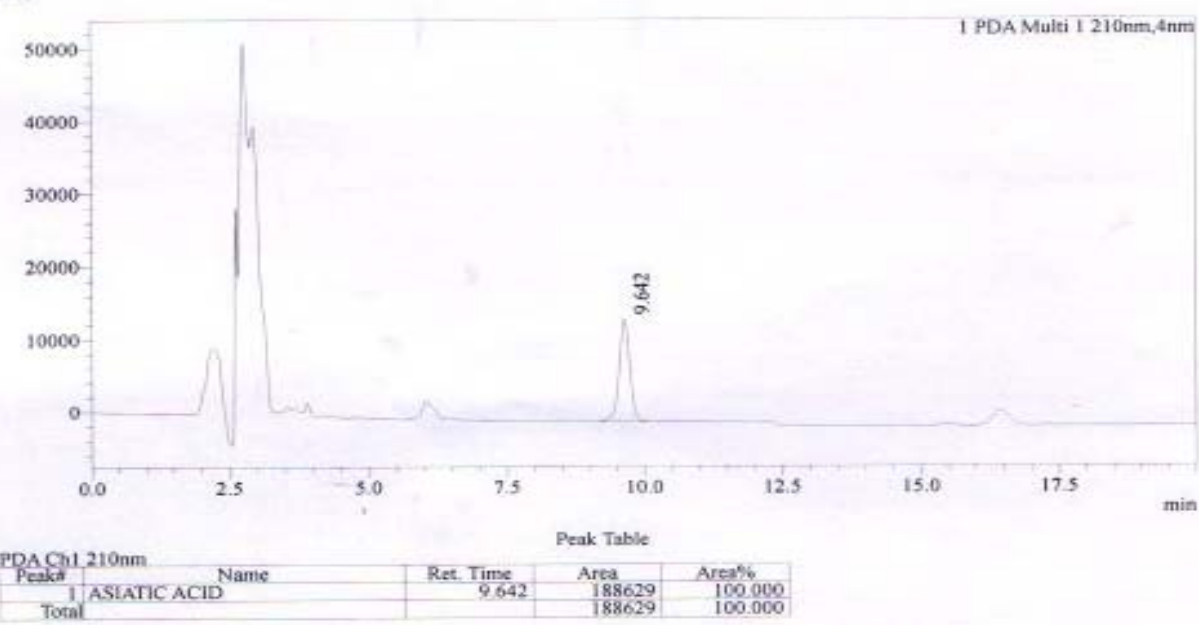

Fig. 5: Chromatogram of isolated asiatic acid 


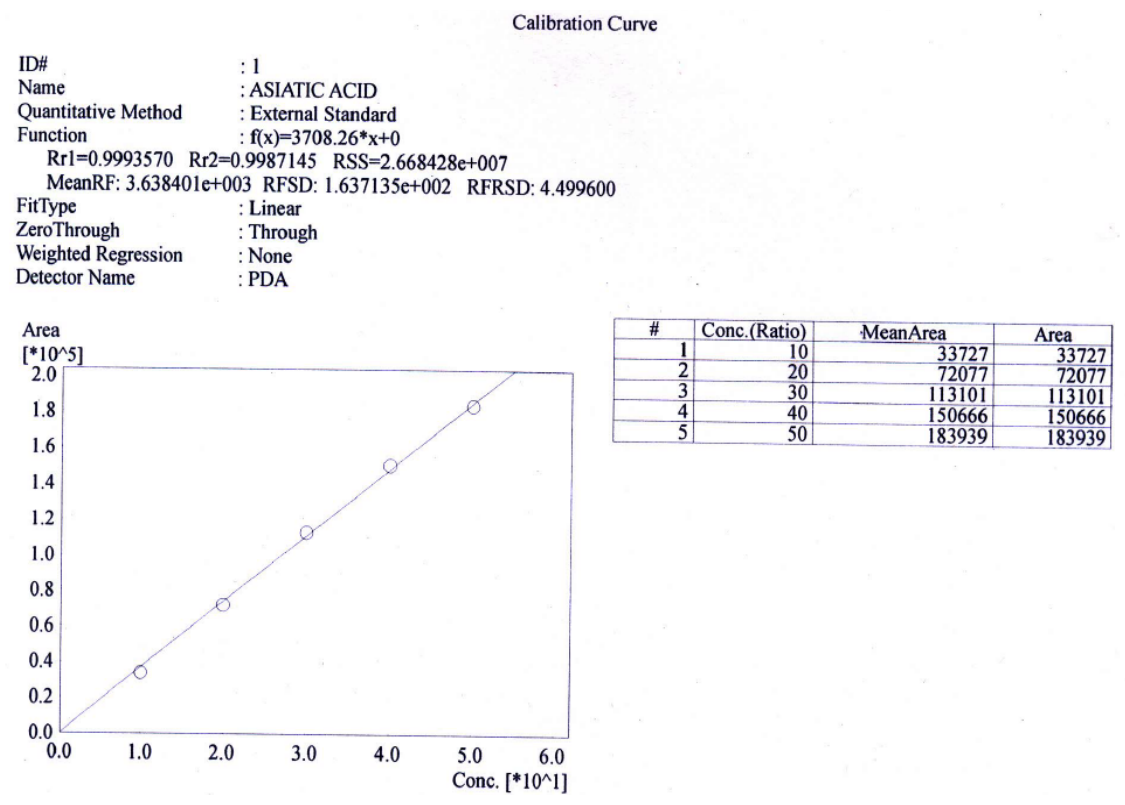

Fig. 6: Calibration curve of asiatic acid

Table 4: System suitability test parameters for asiatic acid

\begin{tabular}{ll}
\hline Parameter & Values \\
\hline \% RSD & $0.529 \%$ \\
Standard deviation & 979.90 \\
Retention time & $9.6 \pm 0.22$ \\
Tailing Factor & $0.907 \pm 0.353$ \\
Theoretical Plates & $11225.5 \pm 0.38$ \\
\hline
\end{tabular}

$* \%$ RSD $=$ Relative standard deviation. $n=6$ samples

\section{LoD and LoQ}

LoD and LoQ were obtained to be $0.784507 \mu \mathrm{g} / \mathrm{ml}$ and $2.615 \mu \mathrm{g} / \mathrm{ml}$ respectively. These values represent that the method is sensitive [17]

\section{Accuracy (Recovery)}

Accuracy studies indicated that the mean recovery of the added standard drug was $99.80 \%$ for isolated asiatic acid.

\section{Precision (Repeatability)}

In the precision studies, RSD of mean assay values was found to be $1.02 \%$. The obtained value is satisfactory repeatability of the method [18].

\section{Intermediate precision (Ruggedness)}

The intermediate precision study indicates that the method is rugged with RSD values of $0.35 \%$ and $0.48 \%$ on different days and by different analysts respectively. By specificity study it was interpreted that there was no interference from impurities or degradation of products. It specifies that the peak response was due to asiatic acid only.

\section{Robustness}

Robustness studies showed that the results of the method remained uninfluenced by minute, intentional changes in the flow rate and column temperature [19]. The RSD of mean assay values was found to be $0.20 \%$ with a flow rate of $0.9 \mathrm{ml} / \mathrm{min}$. and $0.20 \%$ with a flow rate of $1.1 \mathrm{ml} / \mathrm{min}$. Also, RSD of mean assay values was found to be $0.10 \%$ and $0.26 \%$ for the mobile phase compositions 47.5:52.5 v/v and 52.5:47.5 v/v respectively. Since there were no marked changes in the performance characteristics of the method. It was considered being the well applicable method for validation and quantification of asiatic acid [20]. Summary of the study given was below table 5

Table 5: Summary of validation parameters for the proposed HPLC method for isolated asiatic acid

\begin{tabular}{ll}
\hline Parameter & Value \\
\hline LoD $\mu \mathrm{g} / \mathrm{ml}$ & 0.784507 \\
LoQ $\mu \mathrm{g} / \mathrm{ml}$ & 2.615 \\
Accuracy (\% recovery) & $99.80 \%$ \\
Precision (\%RSD) & 1.02 \\
Intermediate precision & $99.83 \pm 0.35 \%$ \\
1. different day & $98.63 \pm 0.48 \%$ \\
2. different analyst & $99.038 \pm 0.106$ \\
Robustness (47.5:52.5 v/v) & $100.79 \pm 0.26$ \\
Robustness (52.5:47.5 v/v) & $111.28 \pm 0.23$ \\
Robustness (0.9 ml/min flow rate) & $91.009 \pm 0.181$ \\
Robustness (1.1 ml/min flow rate) & \\
\hline
\end{tabular}

${ }^{*}$ Formula for $\mathrm{LoD}$ and $\mathrm{LoQk} * \mathrm{SD} / \mathrm{b}$ where, $\mathrm{k}=3$ for $\mathrm{LoD}$ and 10 for $\mathrm{LoQ}, \mathrm{SD}=$ Standard deviation, $\mathrm{b}=$ slope. Number of injections $n=6, n=3$ (Recovery studies) 


\section{CONCLUSION}

Isolation and characterization of asiatic acid were accomplished which will be helpful for standardization of herbal formulations containing this active phytoconstituent. ${ }^{1} \mathrm{H}$ NMR and LCMS spectra confirmed the successful isolation of asiatic acid. The proposed isolation method was found to be effective as the practical yield was satisfactory and the isolated compound was found to be relatively pure. The proposed RP-HPLC method was found to be simple, rapid, specific, accurate and precise for the determination of the concentration of asiatic acid in the methanol extract of Centellaasiatica. Because of the short chromatographic run time (13 min), the developed method can be adopted for the routine quantification and quality control of asiatic acid in various samples from formulations. This method was found to be reliable, robust, and better than the reported HPLC method for asiatic acid.

\section{ACKNOWLEDGMENT}

The authors would like to acknowledge N. G. S. M. Institute of Pharmaceutical Sciences, Nitte (Deemed to be University), Mangaluru for providing the necessary facility to carry out this research work.

\section{AUTHORS CONTRIBUTIONS}

All the author have contributed equally

\section{CONFLICT OF INTERESTS}

Declared none

\section{REFERENCES}

1. Rao MK, Rao MS, Rao GS. Treatment with Centellaasiatica (Linn) fresh leaf extract enhances learning ability and memory retention power in rats. Neuroscience 2007;12:236-41.

2. Chew KK, Ng SY, Thoo YY, Khoo MZ, Wan AWM, Ho CW. Effect of ethanol concentration, extraction time and extraction temperature on the recovery of phenolic compounds and antioxidant capacity of Centellaasiatica extract. Int Food Res J 2011;18:571-8.

3. Patel K, Mishra R, Patel DK. A review on phytopharmaceutical importance of asiaticoside. J Coastal Life Med 2016;4:1000-7.

4. Madhusudhan NCH, Neeraja P, Devi P. Comparative analysis of active constituents in Centellaasiatica varieties (Majjaposhak and Subhodak). Int J Pharm Phytopharmcol Res 2014;4:105-8.

5. Murali KD, Holcomb LA, Hitt AR, Binu T, Porter JW, Young KA, et al. Centellaasiatica extract selectively decreases amyloid $\beta$ levels in hippocampus of Alzheimer's diseases animal model. Phytother Res 2009;23:14-9.

6. Joshi NP, Vaidya VV, Pawar SS, Gadgil JN. Development and validation of HPLC method for simultaneous determination of bioactive markers corosolic acid, asiatic acid and $\beta$-sitosterol from leaves of Lagerstroemia speciosalinn and from marketed formulation. Int J Pharm Pharm Sci 2013;5:223-6.
7. Verma RK, Bhartariya KG, Gupta MM, Sushil K. Reverse-phase high-performance liquid chromatography of asiaticoside in Centellaasiatica. Phytochem Anal 1999;10:191-3.

8. Pandey A, Tripathi S. Concept of standardization, extraction and pre phytochemical screening strategies for herbal drug. J Pharmacogn Phytochem 2014;2:115-9.

9. Sanghavi N, Srivastva R, Malode Y. Isolation and identification of the flavonoid quercetin from tridaxprocumbenslinn. Int J Pharm Sci Res 2016;5:1454-9.

10. Rao SA, Raja B, Dontamsetti BA. New method of extraction, isolation and determination of solanesol from tobacco waste (Nicotianatobacum) by non-aqueous RP-HPLC. Int J Pharm Pharm Sci 2014;6:543-6.

11. Nair SN, Menon S, Shailajan S. A liquid chromatography/ electrospray ionization tandem mass spectrometric method for quantification of asiatic acid from plasma: application to pharmacokinetic study in rats. Rapid Commun Mass Spectrom 2012;26:1899-908.

12. Sahani S, Jain V. A novel RP-HPLC method for simultaneous estimation of berberine, quercetin, and piperine in an ayurvedic formulation. Int J Appl Pharm 2019;11:94-9.

13. ICH Harmonised Tripartite Guideline, Validation of Analytical Procedures: Text and Methodology Q2 (R1); 2005.

14. Desai N, Momin M, Singh U, Khan T, Sherje A. Analytical method development and validation for simultaneous estimation of curcumin and cyclosporine by RP-HPLC. Int J Pharm Pharm Sci 2019;11:26-33.

15. Bonfill M, Mangas S, Cusido RM, Osuna L, Pinol MT, Palazon J. Identification of triterpenoid compounds of Centellaasiatica by thin-layer chromatography and mass spectrometry. Biomed Chromatogr 2006;20:151-3.

16. Bansal NY, Bansal G. HPLC-UV/FD methods for scopoletin and asiatic acid: development, validation and application in WHO recommended stability testing of herbal drug products. Biochem Anal Biochem 2015;4:1-8.

17. Kaur I, Suthar N, Kaur J, Bansal Y, Bansal G. Accelerated stability studies on dried extracts of Centellaasiatica through chemical, HPLC, HPTLC and biological activity analyses. Evid Based Complement Alternat Med 2016;21:127-37.

18. Karthikeyan R, Devadasu C, Srinivasa BP. Isolation, characterization and RP-HPLC estimation of P-coumaric acid from methanolic extract of durva grass (CynodondactylonLinn.). Int J Anal Chem 2015;1-7. http://dx.doi.org/10.1155/ 2015/201386

19. Verma RK, Bhartariya KG, Gupta MM, Kumar S. Reverse phase high-performance liquid chromatography of asiaticoside in Centellaasiatica. Phytochem Anal 1999;10:191-3.

20. Long HS, Stander MA, Wyk V. Notes on the occurrence and significance of triterpenoids (asiaticoside and related compounds) and caffeoylquinic acids in Centella species. S Afr J Bot 2012;82:53-9. 